-writes: "This was a most interesting case, and is the first of its kind which I have seen in my twenty years of practice; its response to irradiation was just what we should have expected.

"After the first week we had to suspend treatment on account of a mechanical breakdown and by this time she had only had a minute dose, yet the tumour was reduced to half its size. She was treated by $\mathrm{X}$-rays at $200 \mathrm{KV}$ with two fields : (i) $5 \mathrm{~cm}$. circular directly anterior; (ii) $6 \times 8 \mathrm{~cm}$. field laterally. The dose given in each field was 1600 units with a thoraeus filter. The tumour dose in this case cannot have been much above 1500 units, which is very small."'

On November 18, 1941, she reported to me before leaving London, and her appearance was as shown in Fig. 2. The optic nerve had been involved for too long to expect any recovery of vision, and this was still as before:

She was seen by Dr. Ross in Boscombe on February 12, 1942, and he reported that " everything seems quite satisfactory. There is still a very slight exophthalmos of the left eye, but it is quite slight; there is no other evidence of any trouble in the orbit and the eye movements are good."

Other suggestions as to the nature of the growth were madè, including "chronic inflammatory," which would not so well account for erosion of the bone and invasion of the sinuses, or for magical disappearance under deep ray therapy in small dosage, and "Boeck's Sarcoid,"' which sometimes disappears spontaneously.

I am grateful to all concerned in the investigation and treatment of this case, and hope that other similar cases will be seen and treated before pressure has produced irrecoverable atrophy of the optic nerve.

\title{
SCLERO-KERATITIS FOLLOWING PHOSPHORUS INJURY OF THE EYE
}

BY

Wing-Commander T. KEITH LYLE, R.A.F.V.R.

and

Squadron Leader AlexandeR G. CROSS, R.A.F.V.R.

A SEARCH of the ophthalmic literature has revealed no record of phosphorus injuries of the eyes. This case is reported because the initial injury is rare and because the long subsequent history, 
resembling delayed mustard gàs keratitis, has caused material damage to the eyes.

\section{Case Report}

R.K., Airman, aged 43 years. History-He served in the Royal Flying Corps in the last war (1914-18). In April, 1918, while he was removing a barrel of phosphorus (used for providing smoke screens) from the water storage tank, it exploded, causing burns of the face, eyes and body. He was admitted to a hospital at Dartford, and apparently recovered in about two weeks. The eyes, subsequently, were red and sore at times, but he did not report to his Medical Officer. In 1921, after leaving the Air Force, he had a severe attack of inflammation of the eyes, lasting about ten months. The eyes were red and painful, and he could not look at a bright light. Similar attacks, though milder in nature, occurred in 1926, 1931 and 1938. The last attack started in 1941, and still persists. His service in the last war (1914-1918) was confined to this country, and it is certain that he was never in contact with mustard gas.

\section{Examination}

Right vision 6/9 $\bar{c}-0.25$ D.Sph., +0.5 D.Cyl., Axis $120^{\circ}=6 / 6$ pt. Left vision $6 / 12 \bar{c}+0.5$ D.Sph., $=6 / 9$.

The eyelids are normal and the ocular movements full. Episcleritis and scleritis of both eyes. The corneae show opacities

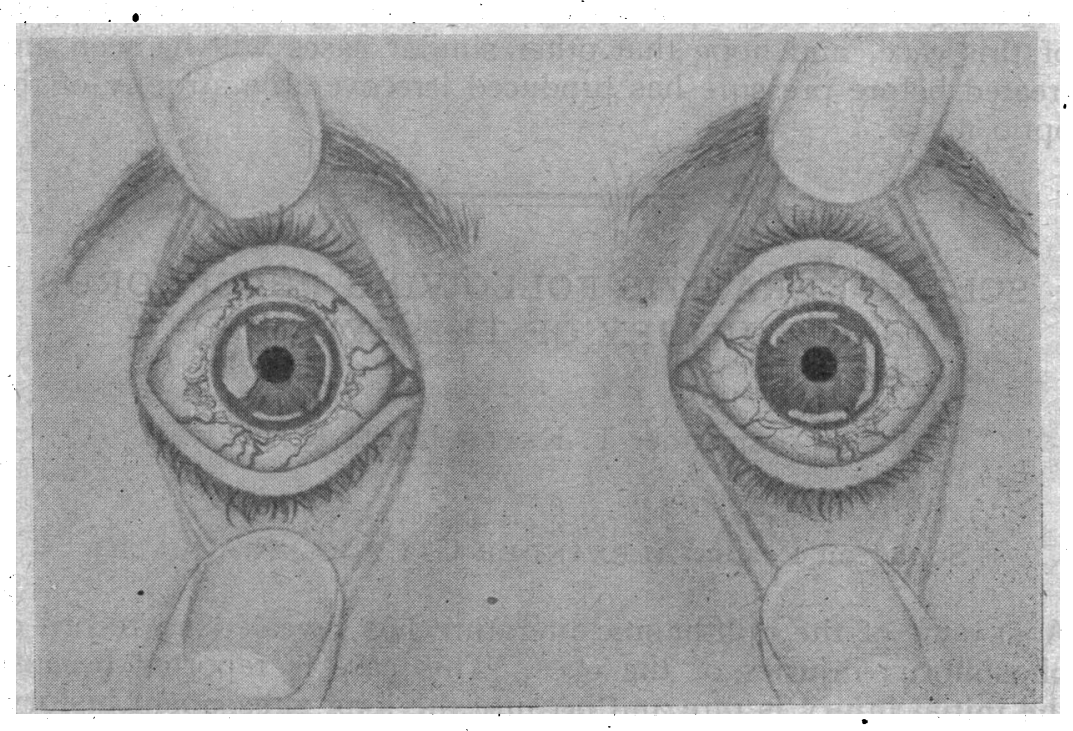


which tend to be close to the limbus, though none actually coalesce with the sclera (see plate). They are situated in the deep layers of the substantia propria and vascularisation is slight except in connection with the largest opacity which is in the right eye and extends anteriorly to the membrane of Bowman. The vessels passing to this are deep in position. Slit-lamp examination shows minute punctate opacities scattered throughout both corneae in the deeper layers of the substantia propria and the presence of crystalline deposits in the scars. There are no "K.P." or synechiae, and no. pigmentary deposit on the anterior lens capsule. The media and fundi are normal. W.R, normal. Examination of nasal sinuses, throat and teeth for infection, shows no abnormality. Radiological examination of the chest is normal. Faint superficial scarring is present on both arms, and on the front of the chest as a result of their involvement in the original accident.

\section{Discussion}

The history of this case, showing recurrences separated by long intervals, resembles mustard gas keratitis, but the clinical features are different. The main lesion is a scleritis and there is no evidence of past corneal ulceration. The corneal scars are, with one exception, deep in the substantia propria, and the irregular vascularisation of the cornea described by Mann and Pullinger in cases of gas keratitis, is not present. The condition of "marbling" of the conjunctiva is absent. The clinical findings in this case differ from the usual type of sclero-keratitis in which the corneal opacity is in continuity with the sclera, and in which uveitis is present. The state of the cornea indicates a degenerative condition and it is suggested that this originated when his eyes were injured with phosphorus twenty-two years ago.

We should like to express our thanks to the Officer Commanding a Royal Air Force Hospital and Air Commodore P. C. Livingston, O.B.E., Consultant in Ophthalmology, for permission to publish this case.

\section{REFERENCES}

Phillips, T. J. (1904).-Proc. Roy. Soc. Med., Vol, XXXIII, p. 229. MÁN, Ida and Pullinger, B. D. (1942).-Ibid., Vol. XXXIII,p. 229. MANN, IDA (1942),-Brit. Med. Jl., p. 353. 